THE APPEAFANCE OF PELLAGRA IN THE UNITED STATES *

\author{
EUWARD JENNER WOOD, M.D. \\ WILMINGTON, N. C.
}

\section{HISTORY OF THE DISEASE}

It is probable that pellagra existed for many years in Europe before its recognition as a distinct disease. For many years it was considered an unusual manifestation of some other disease such as scurvy or leprosy. 'The first indication of the disease in literature was made by Ramazzini, who called it mal del padrone. In 1730 Gaspard Casal, a physician of the Asturias, described pellagra under the name lepra asturiensis. This name is accounted for by the fact that leprosy was at that time prevalent in the Asturias and Casal considered pellagra a manifestation of leprosy. Another author accredits the name lepra scorbutica to Casal. Soon after this it was noted in Galatia, and somewhat later in Castile, Rome and Aragon. Among the people it was variously designated as mal de la rosa, mal del sole, or mal. de la misera. About 1750 the northern provinces of Italy, chiefly in the neighborhood of the Lago Maggiore. became its chief seat and seemed to furnish a much more favorable field for its extension, and, while the disease was still present in the lower Spanish provinces, it never made the same headway there.

Frapolli was the first to apply the name "pellagra" (Italian pelle agra-rough skin). This was about 1 rr. Frapolli asserted that the disease pellarella, which had been known for many years, was identical with pellagra, and that it was present before the introduction of Indian corn from America. Contemporaneously with Frapolli the disease was described by Odoardi in Venetia and called by him scorbutus alpinus. Somewhat later Puyati did important work in showing that all these descriptions and names were for one and the same disease-pellagra.

By 1784 the disease had reached such proportions and the people had hecome so aroused that the Joseph II Pellagra Asylum was established in Legnano under royal authority and the elder Strombio placed in charge. of it. Strombio's work was of the greatest importance and a decided advance in the study of the disease.

By the close of the eighteenth century pellagra had extended into Liguria and Piedmont. In 1818 Hamea, the elder, described it under the name mal de la teste, because occurring in the neighborhood of Teste, and it was at this time that the people bestowed the appropriate name mal de la misera. It was also known as dartres malignes, mal, de sainte-Rose, mal de la sainteMarie and numerous other names of similar character.

Roumania, which is now a stronghold for pellagra, had no recorded case until 1810. This date is associated with the introduction of Indian corn from Italy in coastwise vessels. In 1836 Varnow described it in his inaugural dissertation, and in 1858 Julius Theodori clid likewise. The people knew the disease by the name of Buba Tranitar.

In 1826 Marchand recorded the appearance of pellagra in the southern provinces of France, especially in the rural districts, in the Gironde, in the Pyrenees, and in the Haut-Garonne and the Aude. Recently in these districts it has been greatly reduced, presumably because the corn culture has largely given place to the cultivation of other grain for which the soil is better suited.

* Read by invitation before the College of Physicians of Phila'elphia.
In more recent years Bouchard described the disease ii: Nexico. It has occurred in Brazil, Argentine Republic, Uruguay, and also in Africa. There have been sporadic cases reported from the 'Tyrol, Servia, Bulgaria, (xreece, Asia Minor, anil one case from England. in the sixties Gray of New York and De Wolfe of Nova Scotia reported sporadic cases, but the correctness of the diagnosis was questioned.

Pellagra has without doubt existed in this country for many years, but the appearance must necessarily have been sporadic, for no death-dealing pestilence such as the acute pellagra now so prevalent in the southern states could have been long overlooked.

In 1883 Sherwell reported a case in New York. The patient was a Genoese sailor.

In 1902 Harris of Georgia reported a case simulating pellagra in which he found abundant hookworms. From the description the case must have been well-defined pellagra.

We are indebted to G. H. Searcy of Alabama for the first positive report. He recorded an epidemic of 88 cases occurring in the State Hospital for Colored Insane at Mount Vernon. Of this number 57 patients died. In $1907 \mathrm{~J}$. T. Searcy reported 9 cases from the Bryce Hospital in Alabama. T. C. Merrill in $190 \%$ reported a sporadic case from Texas. Recently, before the medical section of the American Medical Association, R. H. Bellamy reported ten cases seen by him in Wilmington. Bellamy and J. B. Wright of Lincolnton were the first to recognize the disease in North Carolina, and did so before the appearance of Searcy's paper.

Moore has recently reported a case from Augusta, Georgia. Babcock's report to the South Carolina Board of Health aroused much interest in the matter. He described twelve typical cases.

At the 1907 session of the American Medical Association I reported a series of cases under the title of "Symmetrical Gangrene of the Skin," not recognizing their identity with pellagra. I suspected that malaria played a part in the causation of the skin lesion.

In Europe at the present time the chief seats of the disease are northern and central Italy and Roumania. The disease is endemic between 42 and 46 degrees north latitude, 11 degrees west and 26 degrees east longitude of Paris. Several small foci are not included in this area.

In 1879 the number of cases in Italy was 97,855 . About this time in Venetia among 10,000 deaths 500 were due to pellagra. Since 1881 the number has declined materially, supposedly owing to the strenuous efforts on the part of the government in the more careful inspection of Indian corn and in the improvement of the general hygienic conditions. Next to Venetia stands Lombardy, with 300 deaths, then Emilia, with 200 deaths. Piedmont, Umbria, and Tuscanv attribute over 5 per cent. of all deaths to pellagra. Neusser asserted that in 1886 in Venice, with a population of 36.588 natives, there were 1,086 cases of pellagra.

In Roumania in 1885 there were 10,626 cases; in $1886,19.797$ cases out of a pnpulation of $5.300,000$. In 1892 there were 4.500 casec $^{\text {in }} 189821,272$ cases. Triller says that in 1906 in Roumania there were 30.000 pellagrins. From 1893 to 1898 Sandwith reported 500 cases at the Kase el Ainv Hospital in Cairo. In Algiers the disease is well distributed. Triller's idea of the extent of the disease is amazing. He states that in certain parts of Italy in 1906 from 30 to 50 per cent. of the population were affected: that in 1899 the number of cases in all Italy reached 73,000 , which was mort 
than 10 per 1,000 of the rural population. Tuczek asserted that in 1884 there were 10,000 pellagrins in Italian institutions.

Pellagra has extended with great rapidity throughout the south during the past few years. It has been reported from North Carolina, South Carolina, Georgia. Alabama and Texas. I have been able to find reports of 200 cases. Of this number 88 are from the abore-mentioned epidemic reported by Searcy in Alabama, 25 are at present under the care of J. W. Babcock at the State Mospital for the Insane in Columbia, S. C.; 12 were reported by McCamphell from the Western North ('aroilina Hospital for the Insane and 3 from the North Carolina State Hospital for the Insane under the care of J. H. MeKee. In all 65 cases have been recognized in North Carolina; of these, 25 have nccurred in New Hanover county, with a population of about 40,000 .

The disease appears essentially in two forms. In one, the chronic, we have the typical picture described by the Italians: symmetrical erythema, especially of the exposed portions of the body, which appears usually in the spring associated with stomatitis, diarrhea, often some gastric disturbances, and followed by cord symptoms of various kinds, and finally by mental disturbances of varying degree and cachexia. As summer advances the sinentoms usually disappear, only to reappear with the following spring. With each recurrence the impression on the nervous system becomes more indelible, the cachexia more marked, and the skin morc atrophic and discolored. The average duration of these cases in Italy is five years, though not infrequently the duration is twenty years. One of Tuczek's cases was diagnosed as pellagra in 1851 and the patient died of bronchopneumonia in $188 \%$.

\section{REPORTS OF CASES}

The cases here described are illustrative of previously unreported cases, all of which came under my personal observation in North Carolina.

Case 1.-(Dr. Thomas M. Green's case).-Patient.-Mrs. W.. aged 34. Nothing of note in her family or early personal history except malaria. In the spring of 1906 sise suffered with indigestion and diarrhea. One month after the occurrener of these disturbances an erytnema appeared on the backs of her hands, around both eyes, and on the back of the neck which much resembled sunburn. During the summer her condition became improved. In the spring of 1907 she suffered a recurrence similar to what she had had in 1906.

Examination.-In May, 1908, her condition was as follows: A poorly nourished, cachectic woman appearing much olde: than her real age. Situated on her forehead were two areas of desquamating erythema, symmetrical in position, shape and size, between which was a vertical strip of normal skin. Lesions of like character surrounded both eyes. On the upper Iids tine lesions were more recent and were covered with crusts with a weeping surface beneath, extending into t.e anterior nares. The lesions were present below the eyes. There was consider able brownish pigmentation indicating their greater age. On the backs of both hands extending from the finger-nails to the middle of the forearm there existed the moist lesions which were covered with crusts. Over the knuckles and the tip of the styloid the condition was exaggerated, the surface being entirely raw. The lesion was present on the anterior surface and the palms and like the posterior except that the skin of the palms was simply erythematous with exfoliation. Near the margins of the arm lesions there was considerable brownish pigmentation. On the back of the neck was a much older lesion which had caused a tawny discoloration, which posteriorly was about two inches in width but became narrowed as it extended anteriorly. From the two sides the lesion lacked two inches of meeting in front, forming a sort of collar. The labia were affected with a moist lesion. The patient had had an obstinate diarrhea and stomatitis. Physical examination was negative. The urine contained a small amount of albumin and granular casts. The blood showed a simple anemia of moderate degree and no leucocytosis. The differential leucocyte count showed no abnormal variations.

Course of Disease.-When first seen this patient presentad the picture of profound melancholia. As her condition became worse her mental state changed to one of wildest mania, making it necessary to restrain her forcibly to prevent her from leaving her bed. She never spoke, but made incoherent cries anu presented the spectacle of great fear. She refused nourishment when it was offered but would take it if it were left at her side. Her whole body was in a condition of tonic spasm. In her mania the crusts nad been rubbed off from the diseased

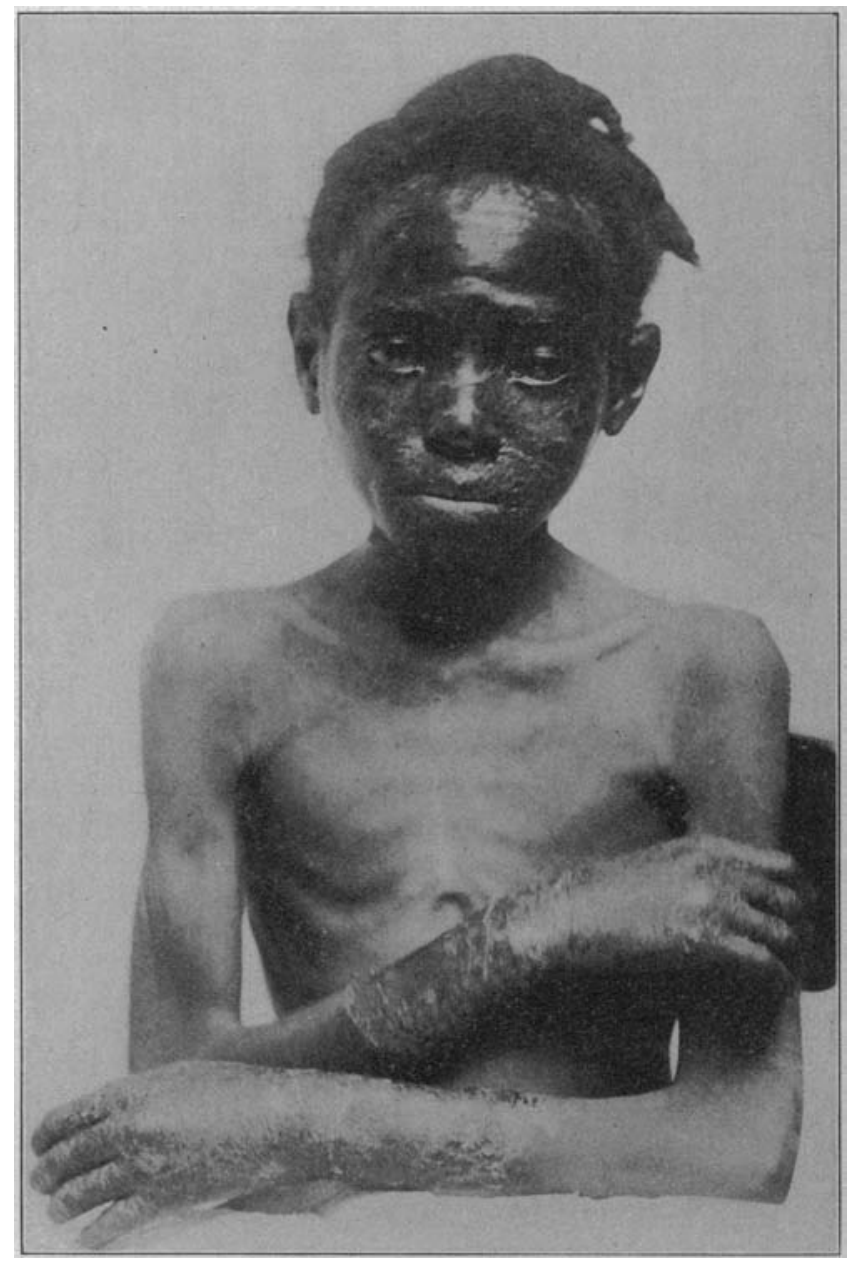

Fig. 1.-Patient 6 : pellagrous lesions on face and hands

areas and the bleeding surfaces made her a loathsome patient. She died about two weeks after her admission to the hospital. Autopsy.-There were general fatty changes in the liver with slight increase in connective tissue around the blood vessels. There was also a slight round-cell infiltration. The capsule was thickened. The kidneys showed moderately advanced interstitial changes. The spleen and adrenals were negative. The changes in the cord were inconsiderable and indefinite save for obliteration of the central canal. The case was not sufficiently chronic to have produced very characteristic nervous changes.

CASE 2.-(Dr. J. B. Wright's case, Lincolnton, N. C.).-X.. femaie, white, aged 11. This patient belonged to the better class. The course of the disease was typical except that she had four attacks in six years, dying in the fourth when 17 years of age. The four attacks began each time in March.

The erythematous recurrences of pellagra usually occur yearly and almost invariably in the spring. One of my earlier cases presented an interesting deviation from this rule. 
CAsE 3.-Patient.-A. R., white, married, aged 46, a grocer. His family and previous history were both negative. He was a magnificent specimen of vigorous, robust manhood. The condition was ushered in with high fever without prodrome-probably an attack of malaria-followed by a profuse sweat and apparent recovery. One week later the patient's strange actions attracted his wife's attention. He would ring his own door-bell and appeared dazed, making many absurd mistakes in his business. This was followed by a general apathy. He suffered from no delusions or hallucinations and there were no sudden outbursts. After six months there appeared, in June, 1905 , two spots of erythema on the backs of his hands. He suffered at this time from diarrhea and had no control over his bowel or bladder. He would lie quietly in bed. His speech was slow and hesitating ana his gait unsteady. His habits were most untidy. The erythematous areas, which were of the dry variety, cleared up and after desquamation the skin was soft and smooth. The patient's mental condition, however, did not

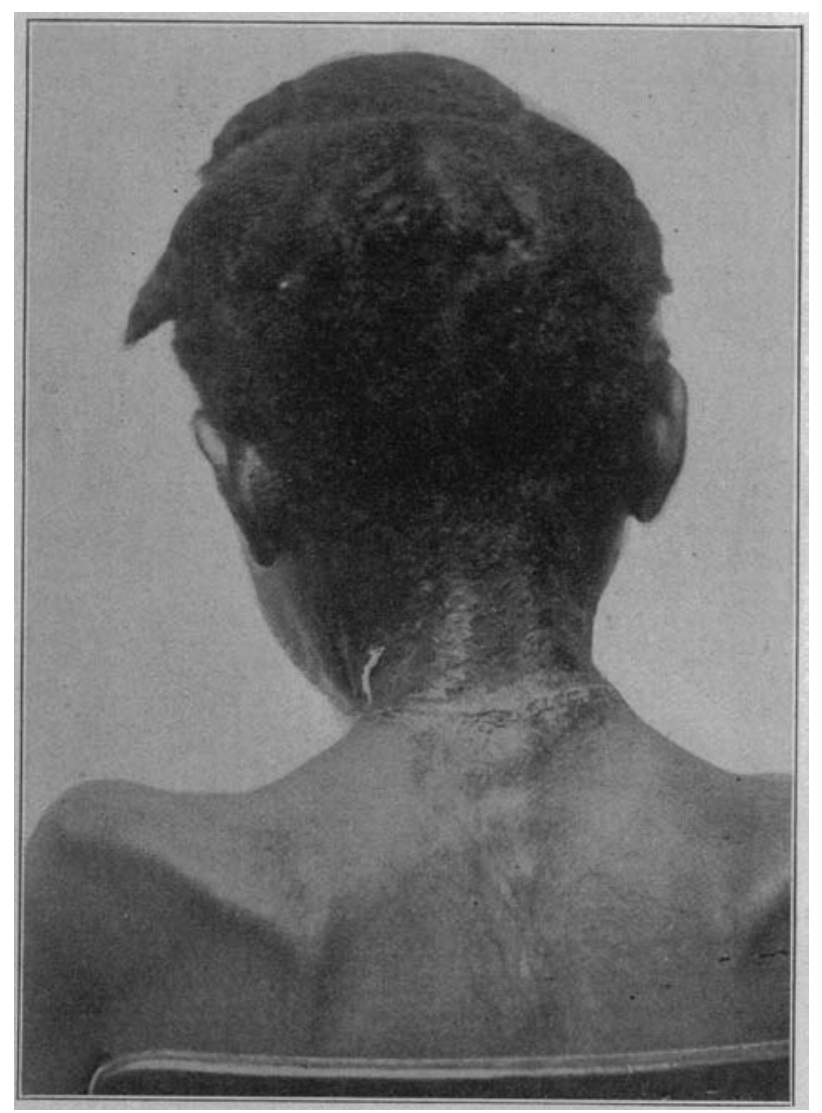

Fig. 2.-Patient 6; pellagrous lesions on back of neck.

improve. In October, 1905, he was admitted to the James Walker Memorial Hospital in Wilmington, N. C.

Examination.-At this time the erythema had reappearsd and extended from the ends of his fingers posteriorly to two inches above the wrist joint. The lines of demarcation on the two hands were symmetrical in the most minute detail. There was also a lesion on the external surface of the right leg. This lesion involved the lower third of the lower leg and the external surface of the foot. It had caused considerable destruetion of the skin. There was a corresponding lesion of smaller size and of the dry variety on the left leg.

Course of Disease.--This patient's blood presented a remarkable condition. For three weeks the blood was loaded with tertian malarial parasites, and a carefully kept chart showed no rise of temperature. At the end of this time the temperature suddenly rose to 105 and the blood showed the preponderance of quartan parasites. From that time his temperature chart showed remarkable variations and the blood showed the preponderance of first one variety of parasites and then another. In the spring of 1909 this patient had his third attack and died in an epileptiform seizure.
From the beginning a case may be classified as acute or chronic without difficulty. Here is a typical case:

CAse 4.-Patient.-D. J., female, colored, aged 21, a field hand, was troubled in February, 1008, with a bloody diarrhea, indigestion, globus hystericus, and leucorrhea. After three months the erythema appeared in the "snuff-box" of the right hand. 'This spot desquamated before the corresponding lesion of the left hand appeared. In June, 1908, she was admitted to the James Walker Memorial Hospital.

Examination.--On the backs of both hands from the finger tips upward was found a dry exfoliating lesion of the skin which was darker than the normal. The upper margins of the two lesions made oblique lines extending from a point at the middle of the forearm internally downward and outward to within one inch of the wrist joint. The same line was carriec out anteriorly and the lesion in this respect was unusual. There were srnall, round symmetrical areas on the upper lids near the inner canthi and at the outer canthi smaller areas. Small areas were found at the angles of the mouth. On the tops of the feet over the ankle joint and also on the tops of the toes were present similar lesions. The patient had never gone without shoes. There was no history of stomatitis.

Course of Lisease.-In July the lesions subsided and the patient was discharged. This was her first attack.

It remains to be seen what will be the course of some of our chronic cases; the patients have survived the first attack, and even the second.

The acute or fulminating variety of pellagra called by Lombroso "typhoid" differs widely from the common Italian form. It runs a course usually of three weeks to three months and invariably ends fatally. The patients usualiy die before any marked nervous changes appear other than those usually incident to a profound acute toxemia. Over 50 per cent. of the cases in the southern states are of this variety. Belmondo and a number of other Italian observers state that this form is never pri. mary; that it is always an exaggeration of a regular securrence of the chronic form of the disease. CAse 5.-(Dr. R. H. Bellamy's case, Wilmington, N. C.) -
Jatient.-B. B., aged 30, white, married. When first seen the disease had existed for several weeks. The patient was much cmaciated and was suffering from an obstinate diarrhea and stomatitis which suggested ptyalism. On the backs of the hands and the posterior surface of the forearms there were found moist exfoliative skin lesions. The same lesions were present on the back of the neck. In the beginning the patient thought he had simple sunburn. In all situations the chief characteristic was absolute symmetry.

After a few weeks this patient diea of exhaustion.

CASE 6.- (Dr. W. J. H. Beilamy's case, Wilmington, N. C.) . Patient.-V. S., negro, female, aged 12, was admitted to the James Walker Memorial Hospital in May, 1908. In February there had appeared at the outer canthi of the eyes two smail red symmetrical areas. These areas extended over the forehead. It next appeared beneath the angles of the jaws and from there around the neck, meeting behind. Soon after the appearance of the skin lesions there developed a severe stomatitis. The next step in the disease was the appearance of the erythema on the backs of the hands, including the fingers. From the beginning there was always an obstinate diarrhea. In May the patient came under my care.

Examination. - At this time the whole face was covered with the lesion which appeared like an old burn and had caused much contraction, producing thereby an ectropion of both lower lids and distorting the mouth. The patient was unable to open her mouth wide enough to permit any examination; she was also unable to close her eyes compietely. Both hands and boti lower thirds of the forearms were covered anteriorly and posteriorly with the moist lesion.

Course of Disease.-Conjunctivitis soon developed and there was marked subconjunctival edema. The feet were edematous and later (several weeks) the lesion appeared on the dorsal surfaces. The knee-jerks were absent; skin sensation normal. The pupils reacted normaliy to light and accommodation. The patient complained constantly of cold. Her appetite at first 
was good but later she refused all nourishment. The affected skin was exfoliated, leaving perfectly raw surfaces. The patient passed eighty round worms during the three weeks she was under observation. She died of exhaustion in June.

In Italy the disease is confined to the peasantry almost exclusively. There poverty and pellagra are interchangeable terms. With us the discase affects all classes alike. In none of the twenty-five cases which I have studied was there a history of a preexisting chronic affection as tuberculosis. As a rule the victims were wellnourished and robust until affected with pellagra.

We have had occasion to consider whether the disease is infectious or contagious, and also whether it is a family disease. The patient just referred to was one of two members of the same family simultaneously affected. The other member was a younger sister, who has the chronic form, and recovered from the first attack. I have seen four children of the same parents affected simultaneously. Two of these patients died suddenly in the first attack. The other two have passed from our observation.

\section{SIGNS AND SYMPTOYS}

A prodrome is acknowledged by all writers on pellagra. This prodrome usually begins about Christma: time and is characterized by indefinite symptoms, such as anorexia or voracious appetite, pain and sensation of distension in the epigastric region, frequently diarrhea, though often constipation, insatiable thirst or the reverse. Later there appears headache, which is chiefly occipital, pain in the back and the neck, hyperesthesias, dizziness, muscular weakness, and uncertainty of motion. Roussel considered sensations of dryness and burning in the mouth and heat in the stomach to be the first symptom of the disease. In nost respects these symptoms present nothing peculiar, but we have learned that when our patient complains of headache, vertigo, sensations of weakness, especially in the lower extremities, together with diarrhea, we should be suspicious of pellagra, especially if the season be late winter or spring. Theodori asserted that these prepellagrous svmptoms existed four weeks before the appearance of the erythema, but in many cases the period is much prolonged.

The erythema almost invariably makes its appearance in the spring. In one series it appeared as early as February and as late as July. The greatest number developed in April and May. The uncovered portions of the body, as the hands, face, and neck, are more apt to be affected and in all cases are first affected. Authorities have always differed in regard to the rôle played by insolation in the causation of the lisease. From our experience we are disposed to reject the idea. The disease usually appears so early in the spring that the sun's ravs ale of little conscquence. Those of our patients who had the lesions of the skin of the feet were in most cases adults who were not in the habit of going without shoes. Further, the skin over the sternum is often affected. Some writers think that the actinic rays are responsible for these lesions of the exposed parts of the body.

The backs of the hands are invariably the first situation of the lesions. This occurred in all of our cases. The lesion in this position is very distinctive and usually furnishes sufficient evidence for a positive diagnosis. The first appearance is often mistaken for sunburn; no two things cou!d be more alike. The lines of demarcation between the normal and diseased skin are absolutely symmetrical in position and direction. The points of greatest intensity are usually the skin over the knuckles and tip of the styloid processes. The lesions usually begin at the ends of the fingers postcriorly and extend upward to the junction of the middle and lower thirds of the forearm. The general appearance is usually that of diffuse redness, without swelling, but in some cases the swelling is added and makes its appearance before the erythema. The condition terminates in dry exfoliation or there may appear blebs, which rupture, leaving raw surfaces, which soon become covered by crusts. The appearance of the skin after healing is variable. It may be soft and velvety like an infant's skin, but there is always a tendency to the disposition of pigment, which increases with each recurrence. In three of our cases the lesion extended to the palmar surfaces, and in this position we always noted the soft, smooth condition of the skin after the lesions disappeared.

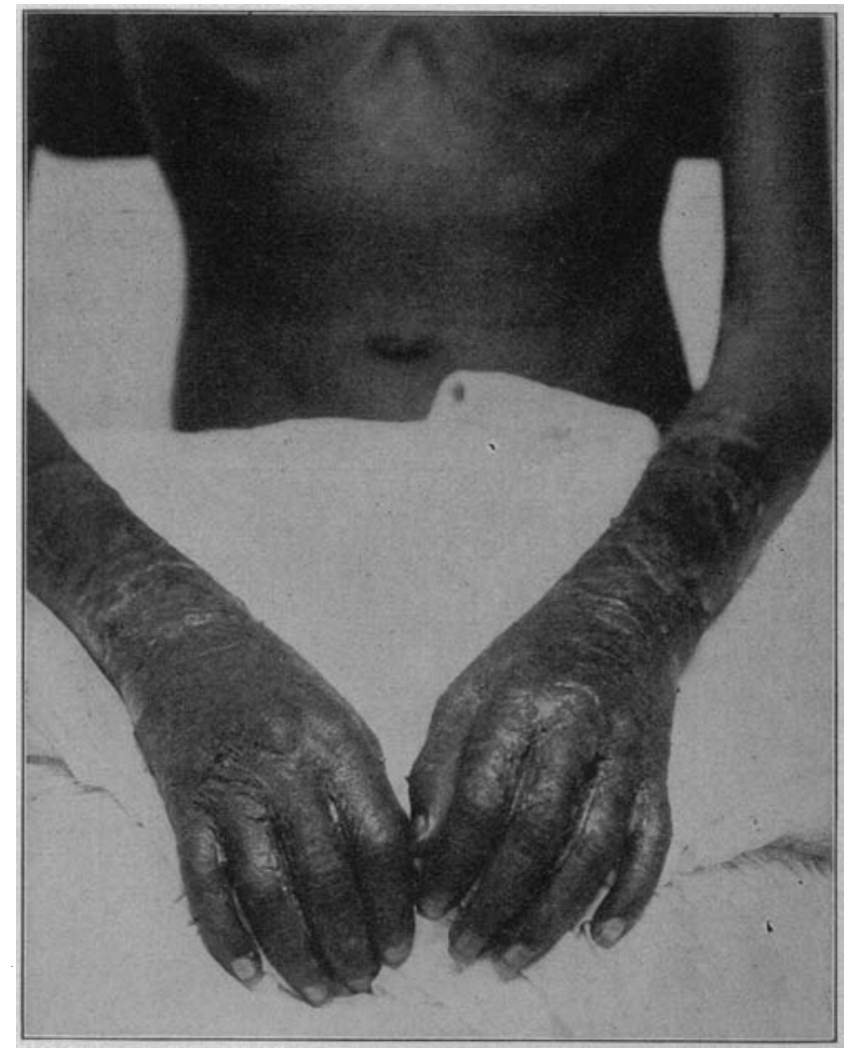

Fig. 3.- Patient 6 ; pellagrous lesions of hands.

After the hands the face is most apt to be affected, and we found this much oftener in women and children than in men. Perfect symmetry is maintained here just as in the hand lesions. Often the first appearance on the face is two small spots at the outer canthi of the eyes or the angles of the mouth. In several cases there were two spots of erythema on the forehead, with a narrow strip of normal skin exactly in the mid-line separating them. Sometimes the lesions assume the butterfly shape of lupus. Small areas below the lower lids are frequent. We have seen the lesions on the back of the neck with a maintenance of the same sym. metry and often there is lateral extension of these le. sions, which may form a collar meeting in front. The next point of selection is the tops of the feet. This occurred in one-third of cur cases. In an acute case the erythema had much the appearance of an acute lymphangitis; begirising over the crest of the tibia and extending downward over the tops of the feet to the toes. As before mentioned, the erythema may appear 


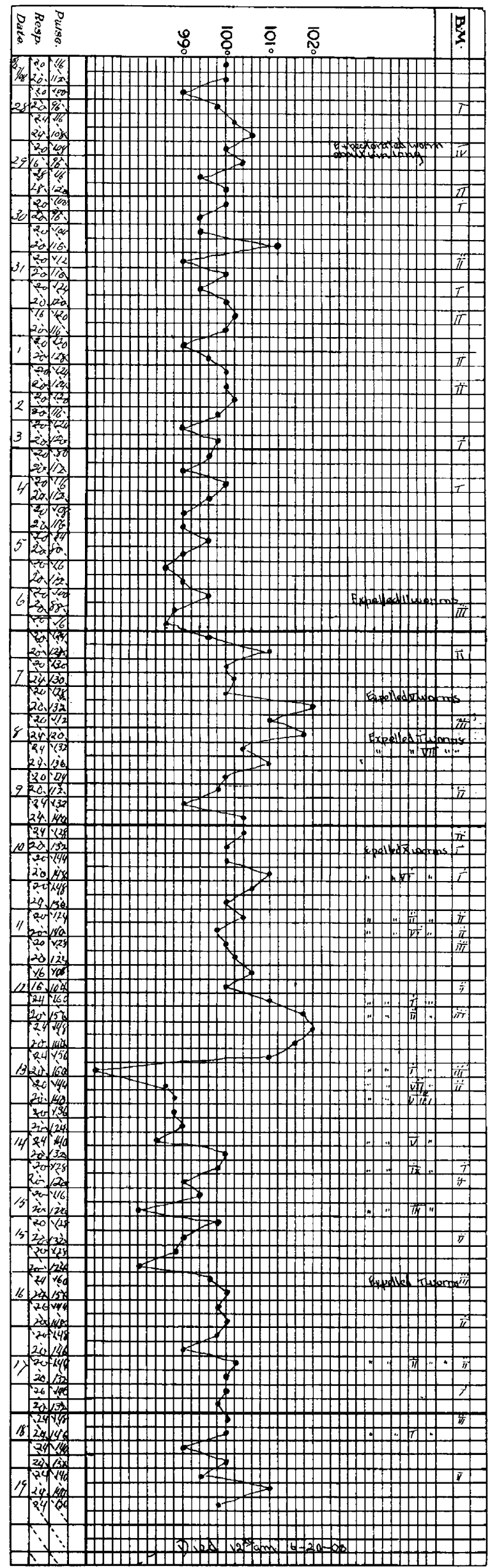

Fig. 4.-Temperature chart of Patient 6 orer the sternum. The labia pudendi are frequent seats of the lesion even in children. With healing there often is associated contraction of the skin as in superficial burns. In Figure 1 marked contraction of the skin of the face is shown, with resulting ectropion and contractions of the skin of the upper and lower lip which made complete closure of the lips impossible. In the dry lesions exfoliation usually occurs after three or four weeks. The resulting pigmentation varies from a slight yellowish tinge to a brown or chocolate, depending on the number of the attacks.

The stomatitis appears usually aftcr the appearance of the skin lesion, sometimes long before, and, again, may be entirely absent. It is a very characteristic symptom and seldom fails to appear at some stage of the disease. It appears like salivation, which, in fact, is often present. The gums are usually swollen and intensely red. The tongue is red and often denuded of epithelium, giving the characteristic "bald tongue." The papillæ are enlarged, with furrows between. The patient complains of the sensation of a salty taste and burning in the mouth. In all our cases the mouth wa: affected in some degree.

The stomach is variously affected. In some cases the hydrochloric acid is normal in amount, while in other it is absent. Pyrosis, eructations, vomiting, anorexia. or bulimia, together with great thirst, have been $\mathrm{cm}$ phasized by various writers.

One of the most unfailing sumptoms is an obstinat. diarrhea, which is most intractable. Sometimes it assumes a dysenteric character with violent colic. Thi intestinal condition is considered by many to be a neurosis.

In the acute form of the disease the nervous disturlances are no more than ordinarily occur in any profound toxemia. It is difficult to say at what stage the nervous disturbances appear in the chronic variety. In one of the cases previously referred to a robust man developed mental disturbances of a peculiar sort and had been in an institution for the insane a number of months before the first appearance of the pellagrous erythema. I recently discovered the first attack of pellagrous erythema in a woman who for several years had been in a hospital for the insane with a diagnosis of melancholia. Can it be that, apart from pellagrous: insanity, the insane are predisposed to the discase?

The first nervous symptoms manifested are usually paresthesias. Chief among those are usually mentioned itching of the backs of the hands and the back, occasionally also of the lower extremities. The patients under my care often complain of pain of a burning character in the right or left scapular region. This latter is a common symptom often referred to. This burning sensation often occurs in the epigastrium, the hands, and the arms, and is supposed to be the caus: of the tendency among pellagrins to throw themselve: into the water whenever occasion presents itself. Numbness and formication are often complained of. One ot the most constant complaints is cold extremities, and it is no unusual sight to find our patients in midsummer huddled before a fire trying to keep warm.

The vertigo of pellagra is a symptom on which much stress is laid by the Italian observers and was seldom wanting in our cases. It is responsible for many falls. By some it is considered a mere lapse of consciousness. According to the careful observations of McCampbell of the Western North Carolina Hospital for the Insane the psychic manifestations were preceded by a period of anxiety and worry with the attachment of undue im- 
portance to trivial things. There is often a simple slowness of ideas. A question is replied to long after the patient seens to have forgotten it. There often occurs an irritable depression with aversion to any activity. Iater there develop disturbances of perception with hallucinations. Judgment may be disturbed, giving rise to delusions which usually are painful and depressive, with a tendency toward fear and suspicion.

Our hospital patients were a great care because of their persistence in disarranging the bed-clothes, attempting to get out of bed, and especially in their total disregard of all cleanliness. We were disposed to consider at first this latter as viciousness, but soon learned that it was mental hebetude. Refusal of food and suicidal tendencies were frequent in our series. As the disease approaches its close the patients become delirious and it is usually necessary to resort to the restraining sheet. They frequently cry out in a wild, incoherent fashion, and in their ravings it is impossible to prevent damage to the skin lesions, with the result that large areas are left raw and bleeding. 'The patient in such cases presents a horrid sight.

A condition is often observed somewhat resembling tetany, with paroxysmal tonic contractions and contractures of the upper and lower extremities in the semi-flexed position. The gait is simple paralitic, occasionally paralytic-spastic, but never ataxic. There is something characteristic, however, in the unsteadiness and secring lack of confidence with which these people shuffle along. Static ataxia is occasionally mentioned. Incoordination is seldom observed, and then only in the upper extremities. Tremor of the arms, head, and tongue sometimes occurs.

Definite epileptiform attacks with loss of consciousness are occasionally observed, having the character of a cortical epilepsy. One of our patients died in such an attack.

The skin sensibility is very irregular. The sense of taste is usually normal. The cutaneous sensibility to the faradic current is often increased. Sometimes there is decrease of tactile and thermal sense. Owing to the altered condition of the patients' intellect and the resulting unreliable character of the replies to questions an investigation of sensation is unsatisfactory.

The skin reflex is usually normal. The pharyngea' reflex is not infrequently decreased. The tendon reflexes are quite variable, often normal, often increased to the point of an intense clonic contraction. Much less frequently they are decreased or absent. It sometimes occurs that the reflex is increased in the lower extremity and normal in the upper extremity. In 'Tuczek's 300 cases one-half had increase in the knee-jerk up to the rapid patellar clonus even with the slightest percussion of the tendon. In thirty-five cases there was dorsal clonus and increase of the tendon refiex of the upper extremity. In eight cases the knee-jerks werf absent and in the remaining it was partly lessened and partly normal. Differences in the two sides were often noted.

Among the vasomotor disturbances is described a vasoparalytic dilatation of the veins and capillaries and not infrequently fdema. The skin lesions are usually counted as trophic disturbances.

Pellagra is usudly described as a feverless disease. Our charts show that during the active stage there is invariably a rise nf temperature ranging from $99.5 \mathrm{~F}$. to $102 \mathrm{~F}$.

The urine is alkaline and deficient in phosphates. When the toxemia is intense there is albuminuria.
What is called by most writers the third slage is characterized by a general atrophy of the whole body; the subcutaneous fat disappears and the patients present the appearance of advanced cachexia. Profound weakness necessitates rest in bed. The bladder becomes paralyzed and the diarrhea is uncontrollable. Death is usually directly attributable to myocardial degeneration and its consequences.

In the very chronic cases there is frequently an acute terminal exacerbation, and it is this condition that the Italians have in mind when they speak of the "typhoid" pellagra. Evidently they are not familiar with the acute pellagra so common with us. This explains Belmondo's statement that "typhoid" pellagra is never primary, but merely an exacerbation of a very chronic. case. It is in this terminal condition that the delirium is so wild. 'Tuczek states that at autopsy fever conld be found to have been due to a bronchopneumonia. In our experience there is just as much cause for fever in pellagra as there is for fever in a large superficial burn which has become infected.

\section{PELLAGRA SINE PEILLAGRA}

"Pellagra sine pellagra" or pellagra without skin manifestations is a point of contention. Some observers consider errthema or atrophy and pigmentation of the skin essential for the diagnosis. Babeock, in South Carolina, at the present time, has a number of such cases under his care. He says these patients have stomatitis, diarrhea and disturbances of the nervous system. Mr own experience is too limited to make the diagnosis without reserve. However, I have under my care several cases which I have diagnosed as "pellagra sine pellagra." One of these patients gives the following historv:

Case 7.-Mrs. U., aged 58, was seized with a peculiar attack which was thought to be apoplectiform. She recovered fro:n the attack but was never quite well afterward. She had repeated obstinate attacks of stomatitis and diarrhea. Five years after the first attack the patient, now aged 63 , is bedridden on account of profound weakness. She has an obstinate diarrhea and is quite emaciated. There is no erythema. She repiies to questions with marked tardiness. The pateilar reflex is absent. The pupils react to light and accommodation in rather an exaggerated degree.

I am convinced that in many of the so-called cases of "pellagra sine pellagra" there is or has been a very" mild erythema which is not visible at the time when the patient comes under observation. All writers on pellagra state that the extent of the erythema is no index to the severity of the disease.

Case 8.-Recently there came under my care a white woman aged 46, mother of eight children, with a negative family his tory and nothing of note in her previous medical history. In July of this year she had an acute gastritis which was quite severe in character. Soon after this she developed diarriea and later a severe stomatitis. She made a slow recovery. During convalescence the palms of her hands and the soles of her feet desquamated. On close inquiry I elicited the fact that early in her sickness her hands had a purplish cast which attracted attention at the time. Careful examination showed the last remnant of the upper border of what must have been the pellagrous erythema. Certainly the lesion was very inconspicuous. At present this patient is a great sufferer. The pain in her hands and feet is constant and her hands show beginning contractures. She is unable to comb her hair or button her clothes. Sho walks with great unsteadiness and says she has the sensation of walking on roller skates. Her station is poor. The pupils react sluggishly to light and accommodation. The knee-jerks are greatiy exagcrerated. Except for increased emotion, the mental condition is little changed. The patient is much emaciated and is losing ground steadily. 
Mistakes in the diagnosis are often made owing to the fact that the order of appearance of the symptoms may be entirely reversed. I have seen stomatitis, diarrhea, and all the mental changes appear a year before the first indication of the skin lesion. It is very likely that in "pellagra sine pellagra" sooner or later there will be skin manifestations.

\section{PdTHOLOGY}

The pathologic changes that occur in pellagra depend largely on the chronicity of the affection. As in ergotism, the most definite changes are in the spinal cord. These changes are just what the symptoms would indicate. In ergotism the posterior root zones are affected, but this does not occur in pellagra. The latter disease shows affections of the lateral rather than the posterior columns. Allbutt says that the weight of the disease falls on the crossed pyramidal tracts; the direct cerebellar tracts are not affected; the cells in the anterior horn are deeply pigmented. The lesions of the posterio: columns occur chiefly in the cervical and upper dorsal. regions while those of the lateral columns affect the middle and lower third of the dorsal region.

In seven out of the eight autopsies which Tuczek reports the posterior columns were degenerated in seven. In one the degeneration was limited to Goll's column and a medial strip in Burdach's column. In five the degeneration extended throughout the whole length of the cord. In one the lesions were found in the cervical portion alone. In four the dorsal region was the chief seat of the disease. In five the crossed pyramidal tract: were affected. In the first the affected areas extended from the upper cervical to the upper dorsal with degeneration of the cells in the anterior and posterior horns in the middle and lower cervical. There was atrophy of cells in the anterior horns and Clarke's column of the upper dorsal. There was atrophy also of the anterior root fibers. In the second the degeneration of the crossed pyramidal tracts was more intense in the dorsal regions, but extended as high upward as the middle cervical and as low as the upper dorsal. In the third case the lesions extended throughout. but was especially marked in the dorsal portion. In the fourth case the lesion was confined to the dorsal portion, and in the fifth degeneration was massive and limited to the middle cervical portion. Tuczek further found abnormal pigmentation similar to senile changes, especially of the ganglion cells. He considered the presence of hyperemia, anemia and edema, together with the occasional inflammatory affections of the central nervous system coverings, as well as obliteration of the central canal of the cordall a part of many chronic affections of the nervous system and, while present in pellagra, they should not be considered characteristic.

The changes in the brain are inconspicuous except for occasional fatty degenerations or calcification of the intima of the smaller vessels and pigmentation in the adventitia.

In one of my earlier cases in which, as was above mentioned, an unusual malarial infection was thought to play a part, the tissues were carefully studied by Dr. H. A. Cotton, Superintendent of the New Jersey Stato Hospital for the Insane. Dr. Cotton reported in part:

The cortex showed no reaction that could be called pathologic. The topography was unaltered and the elements of the cortex were not affected by the malarial infection. There was probably an excess of pigment in the nerve cells which could be accounted for by the patient's age. The blood vessels appeared a trifle thickened but the fixed cells did not seem altered or to have proliferated at all and the vessels were not increased in number. There was no evidence of general paralysis or other organic affections and no evidence of cerebral syphilis. The plasmodia were very easily seen in the blood stream and in large numbers. The Weigert preparation for medullated filser's did not show any degeneration, but in the Marchi preparation there was a scattered degeneration in both cortex and corl. These scattered degenerations probably only meant that there was some toxic effect of the malarial infection. It was only a very moderate degeneration and of little significance.

The stamp on the nervous system can be discovered only after the disease has existed for years. As all of our cases had run only very short courses, the pathologic changes were not marked.

Pigmentation and fatty degeneration of the thoracic and abdominal organs occur. To this is added atrophy chiefly of the organs innervated by the vagus: the heart, kidneys, spleen, intestines, liver and lungs. There is atrophy also of the coats of the intestine with occasional hyperemia and ulceration of the lower portion.

The pathologic changes seem to be slow degeneration rather than inflammation and is probably not essentially progressive in character.

\section{ETIOLOGY}

In $17 \% 6$ the Societa patriotica di Milano offered it prize for a solution of the question of the etiology of pcllagra and a means to combat it. Marzari, in 1810, suggested the relationship of corn in the etiology. Strombio the elder and Marzari asserted that the corn was deficient in nitrogen because it was sown late and gathered green. Forcher and Roussel asserted that it was a disease of the corn which produced the toxin. Lombroso laid stress on the fact that healed pellagrins when given good corn food became affected again. Pellagrins seem to show a susceptibility at certain seasons of the year for even the smallest quantity of pellagrous material. Corn ordinarily contains many micro-organisms and certain parts of the kernel make an excellent nidus. Lombroso concedes that the best corn is often most diseased, and that the trouble is rather in some noxious agent which uses the corn as a host. The $A c a-$ rus farince was supposed to play an important rôle by making a point of entry into the kernel through which the noxious agent entered. Moisture is one of the greatest sources of trouble. The corn, besides being gathered green, is not always carefully handled and is in consequence poorly protected from moisture. It is said that the custom among the Italian peasantry of preserving polenta for days and even weeks, allowing fermentation to occur, is the chief source of danger.

In studying the etiology of the series of cases occurring in my section $I$ was impressed with the fact that practically all of the corn used by the people came from Ohio and Virginia, though in neither of these states had pellagra ever been reported. While by no means ready to accept the corn as the source of the disease, I am os the opinion that, if there is any connection, the noxious agent must appear after the shipping of the corn. Many southern observers attach importance to the heating of the corn which so often occurs in the cars before they are unloaded. Atmospheric conditions probably play an important part.

Last spring I collected three samples of corn which I had reason to suspect of containing pellagrous material. These samples were placed in my laboratory, which during the summer months is a damp place. After an absence of several months I returned to find everything covered with mold. It occurred to me that the conditions were favorable for the development of any fungus. 
and I sent the three samples to the North Carolina Experiment Station. Dr. F. I. Stevens furnished me with the following report:

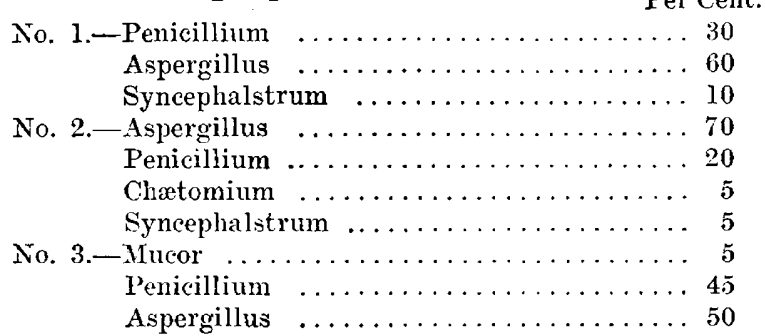

Dr. Stevens considered each sample a good average grade of corn and suitable for food.

Various molds have been brought forward as the etiologic factor. Most common among these is the Penicillium crustaceum, which was not found in any of the corn consumed by my patients.

Lombroso's pellagrozein is said to produce pellagra in animals. While there are toxic symptoms produced, they are not sufficiently typical to be counted as pellagra. 'Two organisms have been isolated from corn. The first is a short bacillus producing an orange-yellow growth on agar-agar, staining by Gram's method and forming no spores. The cultures are abundant and gelatinous. It does not produce gas. This organism is non-pathogenic. The second bacillus produces spores. On agar-agar it produces faint round colonies, which also grow on glycerin agar. It liquefies gelatin. This bacillus, too, is non-pathogenic to rabbits. Its appearance and characteristics correspond with those of the Bacillus mesentericus or with the Bacillus maidis of Peltauf and Heider. This organism was isolated from corn-meal and corn bread, as well as from the feces of pellagrins. It is claimed that this organism is also found in the feces of the normal individual.

Majocchi, in 1881, described the Bacillus maidis as a very motile organism which he found in the blood of pellagrins in the beginning of the disease. Cuboni found the organism in diseased corn and stated that it resisted the boiling temperature. Peltanf and Heider asserted that the Bacillus maidis developed like the Bacillus mesentericus or the potato bacillus and that it was not always present in the feces of pellagrins. They consiclered the organism non-pathogenic, but an alcoholic extract of the corn-meal containing it caused narcosis, paralysis, and death in mice. Babes and Sion produced symptoms resembling pellagra in various animals by the injection of this bacillus. Ballardine, working with the Sporisorium maidis, was able to produce in man gastrointestinal symptoms, but his results were not conclusive.

Tizzoni isolated an organism from the blood, cerebrospinal fluid, organs, and feces of pellagrins. With this orcanism he proiluced, without question, the disease pel. lagra in rabbits and guinea-pigs. Tizzoni also found this same organism in two out of nine samples of suspected corn. In these experiments Tizzoni infected 28 animals. Of this number, 4 were infected by mouth, 3 with pellagrons material and 1 with a culture from the blood of a pellagrin. The remaining 24 were infected subcutaneously, 8 with the blood of a pellagrin, 12 with an organism isolated from the feces of a pellagrin and 4 from corn. The disease so produced ran an acute course of from 16 to 50 days and a chronic course from $8 \%$ to 10 days. Autopsy showed lesions of the skin and abdominal organs of a hemorrhagic type. The changes in the nervous system were varied and indefinite.
Tizzoni and Paniclii, in a previous communication, stated that they could produce the disease experimentally only when, in addition to their inoculations, the animals were fed on corn food.

Lombroso was the chief supporter of the chemical theory of the decomposition of corn as the cause of pellagra. He experimented with great quantities of diseased corn containing Aspergillus, Rhizopus, Bacillus maidis and Ascari. The dogs on which he experimented were fed milk, bread and flesh, and on the administration of his preparation from the corn the temperature rose and the weight decreased. There usually appeared psychic and muscular torpiaity and in some cases anesthesia and tremor. Out of 10 subjects, 7 had diarrhea and in 1 there was an erythema. In all, there were appearances in the dog considered the counterpart of pellagra in man. 'The feeding of bad corn-meal caused erythema, stupor and dysphagia. Lombroso prepared from the corn an oil, a fiuidextract and a tincture. $\mathrm{He}$ gave to 12 individuals daily the corn tincture and in 8 cases there was itching of the back and the face and loss of weight, in 5 cases diarrhea, and in 5 cases desquamation. The appearances were not exclusively those of pellagra, and the result is, therefore, not conclusive.

Neusser believes that corn contains a non-toxic glucoside produced by the Bacillus maidis and that in the intestine this body is decomposed, producing a toxic substance, but that this occurs only when the bowel is already in a diseased condition. There is not sufficient ground for this view.

Antoniu reported seven subjects fed on diseased corn in addition to meat and cheese. Of this number, several became pellagrous, but even this observation is not counted as conclusive, because the possibility of the victims having been previously pellagrous.

Erba's pellagrozein prepared from bad corn caused convulsions, increased reflexes, narcosis and anesthesia. He noted that in summer his product was more toxic.

Babcock, quoting Sambon, says that the association of pellagra with the eating of maize is too universal to be ignored and that, based on pathology and symptomatology, there is good ground for the hypothesis that pellagra is a protozoan disease allied with trypanosomiasis and syphilis.

I have isolated from the blood of a pellagrin in the active stage of the disease a bacillus. It is probable that it is the same as the very actively motile organism described by Majocchi. My observations on this organism are not sufficient for a detailed report at this time. It is altogether probable, however, that Peltanf and Heider, Cuboni, Majocehi, Tizzoni and myself have found at different times the same organism, and that the varying descriptions are accounted for by the polymorphous properties which have been so well described by Tizzoni. This organism is rightly called a streptobacillus by Tizzoni owing to its very short length, often hard to distinguish from a coccus and again by its tendency to occur in chains. It resists a temperature of 90 C. for one hour.

\section{PROANOSIS}

The prognosis of pellagra in this section is very grave. We have many evidences of the fact that when an infertious disease first appears in a comntry it is much more malignant than later on. This is well illustrated in the lower mortality among the Japanese troops in their recent war with Russia from beriberi (about 3 per cent.), while in a new country this mortality often reaches 60 per cent. The same condition obtains in 
measles and yollow fever outbreaks. Fulminating pellawra is an utterly hopeless disease. The death rate of chronic pellagra is very variable, and it is too soon for us to report definitely on this subject. So far we have not observed a case of longer standing than three years.

\section{TREATMENT}

The treatment of acute pellagra is of no avail. We have reason to suspect that the epizootic meningitis among horses is due to the same cause as pellagra in man. If the above-mentioned organism is the cause of pellagra and the horse is susceptible, we have reason to hope that the serum therapy will soon come to our assistance. It has been shown that the blood of a healed pellagrin is curative in guinea-pigs experimentally inoculated with pellagrous material.

In the chronic cases it is possible that a cure may result from the removal of all corn food and general tonic treatment. Atoxyl is much vaunted just now, but in our hands the resilts have not been so brilliant as reported by the European writers on pellagra.

In closing I wish to express to my fellow practitioners of North Carolind my appreciation of their generous assistance in collecting data for this paper and also to the officials of the James Walker Memorial Hospital for the privileges of their wards.

The following norks may be of interest to those who mav desire to pursue the subject further:

Thiery: Recueil périodique de médecine et de chirorgie. Pal'is, 175), ii. 337: Observations de médicine faites en Espagne, Paris, 1701 , i, 109.

lirapoli. Animad in morbo rulgo pellagr. med. 1771.

Hamazzini: Maladie des artisans traduit par Fourcroy, Paris, tamazzib

Strambio: De pellagia obs. med.. 1790.

Boismont: De la pellagre et de la folie pellagreuse, Paris, 1834

Roussel, Th.: De la pellagre, I'aris, 1845; Bull. de 1'Acad. de méd., xii, p. 929 .

Schedel: Abrégé pratique des maladies de la peau, ed. 4. 1847. Baillarger: De la paralysie pellagreuse, Bull. et Mem. de l'Aiad de méd. Paris, 1848, xiii, 708

valleix, F. L. 1.: Guide du medicin practicien, Paris, 1853. v, 304.

Tuczek. F.: Klinische und anatomische Studien iber Pellagra, 1893

Procopin. G. : La pellagre. 1903

Harris, H. F. A Case of Ankylostomiasis Presenting the symptoms of Pella orra 'Tr. Med. Assn. Georgia, 1902. p. 220.

cerconi, II. : Frythemes pellagreus et E. pellag., Thesis, Paris, 1903 .

Allbutt. A System of Medicine. 1905, ii. 800

'l'iller, B. : La pellagre. Thesis, l'aris, 1906.

Sandwith, F. M. : Pellagra in Egypt, Brit. Tour. Dermat., $x$.

Lombroso, $\therefore$ : Die Lehre von der Iellagra.

Babes and Sion: Die Pellagra, Nothnagel, Spec. Path. u. Therap. 1901, xxiv, Hefte ii, Abt. ii and jii, p. 1.

Radcliffe, Crocker H.: Diseases of the Skin.

Manson, Sir I', : 'Tropical Iriseases, ed. 4

Tizmoni, (*. : Nuove ricerche batteriol. sulla pellagra. Gazz d. usp. e d. elin.. December. 1907. No. 147 ; Centraibl. f. Bakteriol. fyi No. 4, part 1: Intorno alla pathogenesi ed etiologica della pellagra : contributo batteriol. e sperimentale, Rome, 1909.

rizsoni and Fasoli: Saggio di ricerche batteriol. sulla peltagra, Memoria dell'Acad. dei Lincei, vi, Sed. i. April, 1906.

Tiszoni : and Panichi: Ulteriori ricerche sperimentali sulla pel lagra, $\mathbf{R}$. Acead. d. se. dell'Istituto di Bologna. Rendiconti, Sessione 24, February, 1907; Centralbl. f. Bakteriol.. xliv No. 3 , part 1 .

Merroll, $\mathbf{T}$. C.: A sporadic Case Diagnosed as Pellagra. 'PtF Jourval A. M. A.. Sept. 14,1007 , xliv, 940

Searcy, G. H. An Epidemic of Acute Pellagra. ibid.. July 6. 1907, xlix, 37 .

Babeck, J. WW. : Am. Jour. Insan. lxiv, No. 4 ; Jour. South Carolina Med. Assn., November, 1008.

Rellamy, R. H. Pellagra: Its Occurrence in This Country : Re port of Cases, The Jofimal A. M. A. Aug. 1. 1908, li. 396.

Moore, N. M. : I'ellagra : Report of Case, with Remarks on Etiology. Sept. 26, 1908, 1i, 1076; Tr. South Carolina Med. Assn. November, 1908

Wow, E. J.: A Mixed Infection with Teltian and Quartan Ma

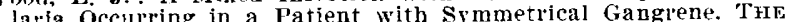
lorla occrin a Gotral. A. A. A.. Pec Coll Phys of Philadelphia Series Nulth Carolina, 1908: Tr. Coll. Phys. of Philadelphia, series. 3. xxx 196: Jour. South Carolina Med. Assn. Novil, 1908.

Mec'ampbell. I.: Tr. Med. Soc. North Carolina. 1908: Joul. South Carolina Med. Assn.. Torember, 1908.

Lavender, C. H. : I'eltagra, Report C. S. P. H. and M.H. S., 1008.
THE VITALITY OF THE IIENTAL ENAMEL *

\section{R. R. ANDREWS, A.M., I).D.S.
CAMBRIDGE, MASS.}

$M y$ interest in this subject has been renewed recently by being shown some very beautiful sections and photographs of enamel prepared by Dr. C. Francis Bodecker, of Berlin. The sections were decalcified by the celloidin decalcifying method which stains the tissue at the same tince. The photographs were made by the ultraviolet light. These enamel sections were shown me while Dr. Bodecker was visiting America a few months ago, and are the result of his own work on the research of this subject. He very kindly gave me a section that he had prepared by this method, which was very thin, and which was stained to show the semblance of living tissue between the rods of enamel, which he offers as a possible proof of his father's theory that there are living fibers between the enamel rods. I have given to the study of this section close attention and with the highest powers of the microscope at my command. Of the results I shall speak later.

Dr. Bodecker is the son of Prof. C. F. W. Bodecker, the author of "The Anatomy and the Pathology of the Teeth," a work which created considerable discussion among the authorities at the time of its publication in 1894, on account of its acceptance of Professor Heitzmann's peculiar views.

Professor Bodecker believed that the enamel is traversed by fibers of living matter located in the interstices between the enamel rods. He states that the fibers are connected with one another by delicate fibrillæ piercing the enamel rods in a vertical direction. Besides these rectangular unions, he asserts that the basic substance is traversed by a minute network of living matter, that the enamel fibers send conical thorns toward the enamel rods, and that such thorns are visible in all interstices between the enamel rods. He also says that the enamel fibers are continuous on the outer surface with the cover. ing layer of flat epithelium, and, on the inner surface with the dentinal fibers, that the latter connection is either direct or indirect through a network of living matter or through intervening protoplasmic bodies in the interzonal layer.

A promise made several months ago to your Secretary to discuss the subject of the vitality of the enamel is my excuse for the presentation of this paper. It has bcen a battle-ground for discussion by the forces of the Heitzmann theory, in opposition to eminent authorities both in this country and abroad for many years.

In order that we may understand the subject better, I shall describe the formation of the enamel organ with its lavers, as it is formed on the cusps of the dentine germ just before the formation of the dentine-forming cells, the odontoblasts. The ameloblasts appear in the enamel organ over the dentine germ as columns of cells while the outer cells of the dentine germ are as yet simply unaltered connective tissue cells. The enamel organ. at its first stage, is a club-shaped ingrowth from the Malpighian layer of the epithelium into the connective tissue which is covered by it. This appears at about the forty-eighth day of embryonic life. As it forces its way into the connective tissue, it expands at its base, and the cells within are multiplying and differentiating, rapidly assuming a stellate form, and causing an expansion at the hase of the organ. As it enlarges, it enfolds the growing dentine germ, covering it on all sides except

* Read in the Section on Stomatology of the American Medical Association, at the Sixtieth Annual Session, at Atlantic City, June, 1009 . 